\title{
Effect of Filler Grain Size on Some Physical Properties of Nano Composite Based On Blend Matrix
}

\author{
Muna M. Shalaan ${ }^{\mathrm{a}}$, Ahmad H. AL-Falahi ${ }^{\mathrm{a}}$, Balkes M. AL-Dabagh ${ }^{\mathrm{b}}$ \\ ${ }^{a}$ Department of Physics, College of Education for Pure Sciences, University of Anbar, Iraq. \\ ${ }^{b}$ Department of Applied Sciences, University of Technology, Iraq.
}

\begin{abstract}
This research studies the effects of particle grain size of reinforcing material on mechanical properties of composite material. A polymeric blend of epoxy resin and poly sulphide rubber [Ep 70\% + PSR $30 \%$ ] was used as a matrix, and nanozirconia powder (Nano-ZrO2) as a reinforcement material with various grain sizes (20-40) nm, (40-50) $\mathrm{nm}$ with the same weight fraction (2\% wt.), and research samples were prepared by Handle Lay-Up Modeling.Tensile Strength, Hardness tests and the study of Surface Topography were conducted using a scanning electron microscope (SEM) without immersion and after immersion in normal water for 10 weeks, and the inspection of absorbency material.The results of the tests before immersion revealed that reinforcement by zirconia nanoparticles powder improves the mechanical properties, especially in the case of small grain size (20-40) $\mathrm{nm}$ as composites recorded highest tensile strength (5.93 MPa), and the highest hardness of the surface (57), while it was less so in the case of big grain size (40-50) nm tensile strength it (2.036 MPa) and surface hardness (41).Absorbing material for water, after immersing the samples in ordinary water, negatively influenced the mechanical properties with the exception of increasing the hardness of the surface at the end of the period of immersion.
\end{abstract}

Keywords : Blend ,Grain Size ,Hardness, Mechanical properties, Nano Zirconia, , Tensile,.

\section{INTRODUCTION}

Industrial and technological development of the modern world is witnessing advancement in various material fields, especially the advanced materials used in high technology. Therefore, there was a need for materials and with high quality and low costs to be used in the Hence various industrial applications such as aircrafts, radars, ships, vehicles., others Composite materials was developed. The nanocomposite materials, with polymeric basis, is considered one of the most important advanced materials that contribute to solving intractable problems in several areas of life and industry [1]. For polymeric composite materials with certain specifications, which cannot be obtained from the use of one type of polymers, numerous attempts to mix the two or more types of polymers and get the blend with the desired industrial specifications to be used as a matrix material. The polymeric blend is a mixture of two or more polymers physically without the presence of covalent bonding and the blend has properties that change depending on the proportions of the basic components.

The thermosetting addition of rubber polymers such as Poly Sulphide to thermosetting polymers such as Epoxy works to increase the viability of elongation and reduce the modulus of elasticity and tensile strength and the polymer becomes less brittle with decreasing of $\mathrm{Tg}$. This physical transformation of a significant economic and industrial interest [2].

The behavior of the phase balance of blends can be controlled by the free energy of the blend as in equation (1):

$\Delta \mathbf{G}_{\text {mix }}=\Delta \mathbf{H}_{\text {mix }}-\mathbf{T} \Delta \mathbf{S}_{\text {mix }}$

Where:

$\Delta \mathrm{G}_{\text {mix }}$ :

change

change in

in

free

The

free energy

of the blend
of the blend

(J).

$\Delta \mathrm{S}_{\text {mix }}$ : The change in the entropy of the blend (J/K).

Depending on the temperature of the blend, and for the blend to be homogeneous, $\Delta \mathrm{G}$ mix value must be negative and fulfills the following condition [3]:

$\left[\frac{\partial^{2} \Delta \mathbf{G}}{\partial \varphi_{\mathrm{i}}^{2}}\right] \mathbf{T}, \mathbf{P}<\mathbf{0}$

Where:

T: Heat Temperature $\left({ }^{\circ} \mathrm{C}\right)$

P: Pressure $\left(\mathrm{P}_{\mathrm{a}}\right)$

$\varphi \dot{i}$ : Weight fraction of the compound.

II. EXPERIMENTAL 
The polymeric blend was prepared by mixing Epoxy Resin (70\%) and Poly Sulphide Resin (30\%). The epoxy used (Poly Prime), by Henkel Polybit Co. United Arab Emirates (UAE), is a transparent liquid with density $(\simeq 1.039 \mathrm{~g} / \mathrm{cm} 3)$, average viscosity, adhesive ability, low shrinkage and viable treatment to the solid state by adding tempered (Hardner) 1: 2 ratio. The interaction occurs in the laboratory room temperature, and the epoxy polymer is (Thermoset Polymer).The poly sulfide is a type of Rubber Polymers with density $(1.35 \mathrm{~g} / \mathrm{cm} 3)$ manufactured by Henkel Polybit Co. and is also a strong rubber material capable of processing into solid state with the addition of its tempered material by the ratio and by (1:2). Nanoscale zirconia powder (Nano-ZrO2), manufactured by EPRUI-Nano Particles \& Microspheres Co. Ltd, China, was used as reinforcement material with two different sizes (20-40) $\mathrm{nm}$ and (40-50) nm and the same weight fraction of (2\% wt.) using equations (3 \& 4) [4].

$$
\begin{aligned}
& \Psi=\frac{\mathbf{W}_{\mathrm{f}}}{\mathbf{W}_{\mathrm{c}}} \times 100 \% \\
& \mathbf{W}_{\mathrm{c}}=\mathbf{W}_{\mathrm{f}}+\mathbf{W}_{\mathrm{m}}
\end{aligned}
$$

Where:

$\Psi$ : weight fraction of reinforcement material in composite material.

$\mathrm{W}_{\mathrm{c}}, \mathrm{W}_{\mathrm{m}}, \mathrm{W}_{\mathrm{f}}$ : weight fraction of composite material, matrix material and reinforcement material.

\section{1: Sample Preparation:}

Hand Lay-Up Modeling was used to prepare the following research samples:

1. Unsupported Polymeric blend samples (Ep+PSR)

2. Supported polymeric blend composite, with grain size (20-40) $\mathrm{nm}$.

3. Composite blend supported by zirconia, with grain size (40-50) $\mathrm{nm}$.

After the completion of the casting process and heat treatment required for the completion of the polymerization process, the samples were cut to forms and dimensions for each test, according to standard specifications (ASTM).

2.2 : Tests

Tensile strength, surface hardness tests and the surface topography of the material were conducted for samples before immersion in normal water and after immersion, and effect of absorption of the water on their properties was studied. All tests were conducted under laboratory room temperature.

\subsection{1: Tensile Strength Test}

The tensile testing is one of the important mechanical tests of composite material to understand its engineering properties, such as elastic modulus and material ductility and strain, and yield point and tensile strength.

JIANQIAO TESTING EQUIPMENT (JTE) was used to estimate the tensile strength of the specimens material using equation (5) [5].

$$
\text { T. } \mathbf{S}_{\max }=\underset{\text { Where: }}{\frac{\mathbf{F}}{\mathbf{A}}}
$$

$$
\text { T. } \mathrm{S}_{\max } \text { : Maximum tensile strength }\left(\mathrm{N} / \mathrm{mm}^{2}\right)
$$

F: Applied force at failure $(\mathrm{N})$

A: The cross-section area of the sample $\left(\mathrm{mm}^{2}\right)$

\subsection{2: Surface Hardness Test}

Hardness test is one of the important mechanical properties of the surface and hardness can be defined as the resistance of material for stitches or Indentation in its surface. Hardness property relates to other variables such as the modulus of elasticity, yield point, eliminate strain and permanent deformation and these effects depends in turn on the bonding force between molecules or atoms article, as well as the type of surface, temperature and rate of deformation.

Shore Durometer Hardness (Shore-D) for this research to study the hardness of the surface of the sample material. [6].

\subsection{3: Water Absorption}

The samples were immersed in ordinary water for 10 weeks. The weight gain $\%$ was calculated and the relationship with the square root of the time of immersion was configured, as shown in Figure 3.

A mass of each sample has been appointed before immersion in water using normal electronic balance accurate and sensitive to four decimal places $(0.0001 \mathrm{gm})$, and then the samples were immersed. The amount of water absorbed was determined and then the percentage change in the mass was determined by equation (6) for different periods of time and on a regular basis [7]. 
Weight Gain $\%=\frac{m_{2}-m_{1}}{m_{1}} \times 100$

Where:

Weight

$\mathrm{m} 1$ :

Gain

mass

$\%$ :

: The

of

the

$\mathrm{m} 2$ : mass of the sample after immersion (g)

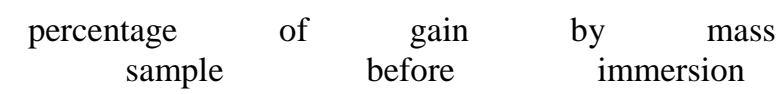

\subsection{4: Surface Topographic}

Scanning Electronic Microscope (SEM) was used to obtain information on the material's surface and study the effect of reinforcing and absorption of water on it.

\section{1: Tensile Test}

\section{RESULTS AND DISCUSSION}

In normal conditions (without immersion) composite supported with zirconia with small grain size (20-40) $\mathrm{nm}$ (Sample 2), with the highest tensile strength (5.93MPa), followed by the unsupported blend (Sample 1) (2.75MPa), while the composite supported by zirconia with big grain size (40-50) nm, ( Sample 3 ) has the least strength, (2.036MPa), as it shows a Figure 1.

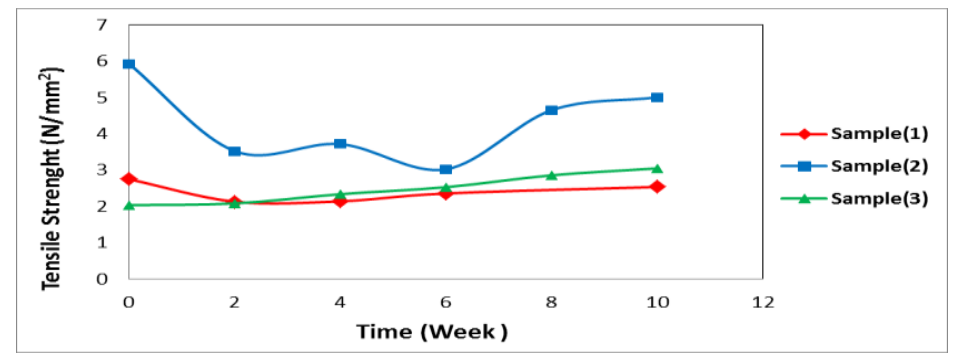

Fig.1: Variation of tensile strength before and after immersion into $\mathrm{H} 2 \mathrm{O}$

The fact that the high tensile strength in the model (2) goes back to the small grain size for zirconia which facilitate the penetration into the matrix material (the polymeric blend) and into the intra-pores that arise during the process of preparation and this helps to increase the contact area between the components of composite material, and then interdependence among them which led to increased resistance to tensile [8] .

After water immersion a decrease in tensile strength in general for all samples was observed and in particular sample (2). This's due to the fact that zirconium oxide ceramic material is brittle with little ductility which leads to a decrease in the tensile strength [9].

On the other hand, immersing polymeric material in water generates cracks where these cracks grow forming larger ones with increasing duration of immersion leading to a decrease in tensile strength.

In other cases, the fracture starts at the outer surfaces of the scratches sites or internal cracks which work as stress concentration zones and the stress rises to exceed the limits of the power of the internal tensile bonding on both ends of the sample resulting in crack [4]. On the other hand, the poly sulphide is an ideal flexible polymer rubber, and is prone to distortion in its viscous behavior under tensile effect [10].

\section{2: Hardness Test}

In normal conditions, the results of tests set forth in Figure 2 shows that composite material ( sample 2) has the highest surface hardness while ( sample 1) (Ep + PSR) had the lowest hardness. The low hardness of the polymeric blend is due to the plasticity and rubber, which poly sulfide monomers has added to the epoxy and spacing distances between the polymeric chains from each other [11].

On the other hand, the addition of zirconia particles, a ceramic material characterized by high hardness and resistance to the plastic deformation, penetrates inside the matrix material and into the glades interfaces and distances that formed during the preparation of composite process, has helped to increase the contact area between the components of composite material and increasing interdependence among them a what can be treated as an addition cross linking in the polymer network leads to increased composite hardness [12]. 


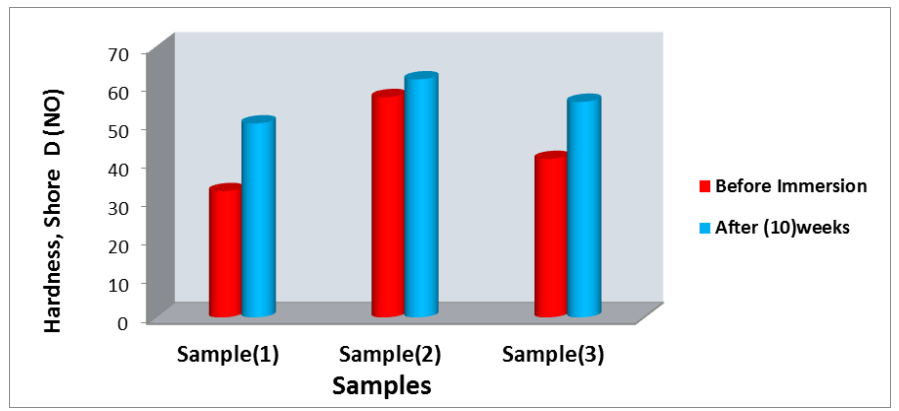

Fig.2: Variation of hardness before and after immersion into $\mathrm{H} 2 \mathrm{O}$

\section{3: Water Absorption}

Figure 3 illustrates the water spread in the samples to a varying degree, and the absorbency of composites was higher than the polymeric blend. This is because that the zirconium oxide is a ceramic material, characterized by its proximity to the many interfaces spaces, and the fact that the water of a low molecular weight which makes it easier for penetration into the pores and this causes changes in material such as Plasticizer, cracking and hydrolysis [13].

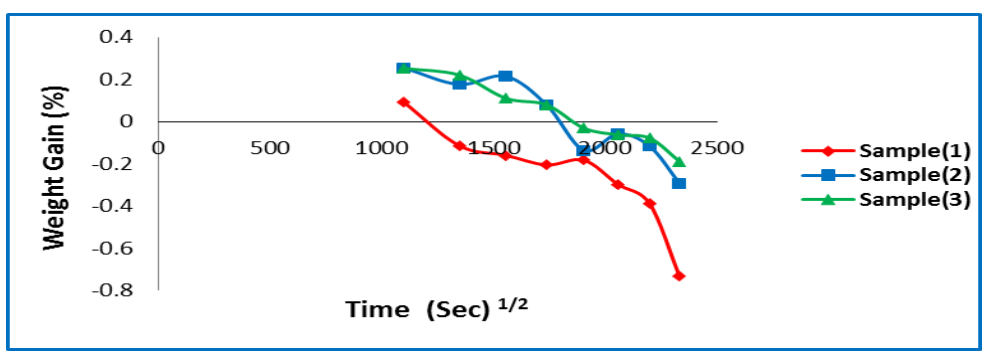

Fig.3: Relation between W.G\% and time of immersion

\section{4: Scanning Electronic Microscope}

SEM images shown in Figure (4) revealed that the surface of the material before immersion seems strong cohesive and soft and that this means that the zirconia particles immersed in the polymeric blend uniformly, whereas images after water immersion has shown a change in the topography of the material surface. The presence of some of the gaps on the surface and the phenomenon of indentation and polymeric erosion were observed [14].

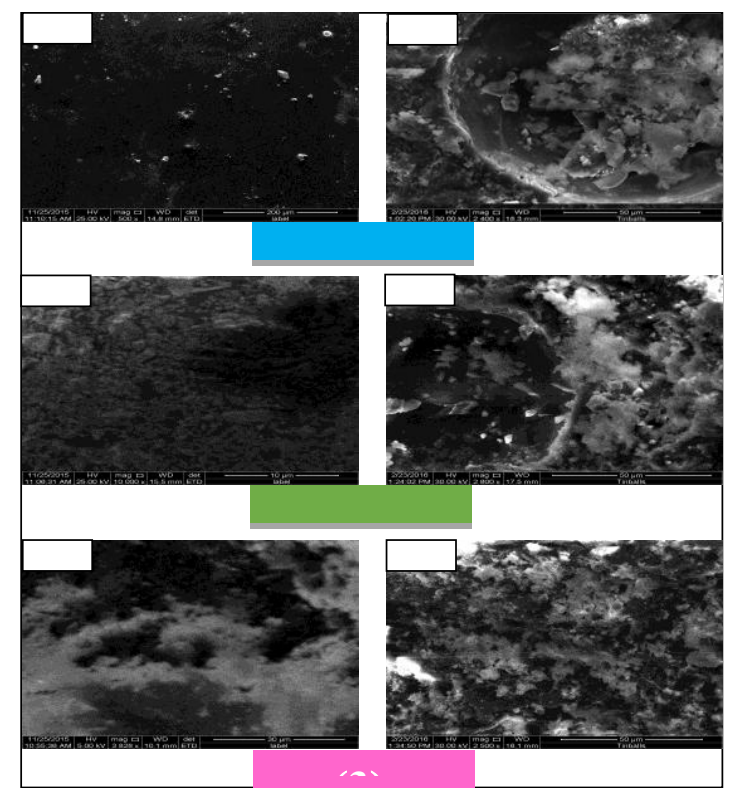

Fig. 4: SEM images of samples (a) without immersion, (b) after immersion into H2O 


\section{CONCOLUSIONS}

The following conclusions can be drawn:

1. Adding zirconia nanoscale powder led to high tensile strength and hardness of the surface of the polymeric blend.

2. The different grain size of the supporting material affects the properties of the composite material.

3. Exposing the polymeric blend and it's composites to immersion in water led to decreased tensile strength of the material and increased the hardness of the surface, and the surface is affected in a negative way.

4. The absorption of composites to water is higher than that of the polymeric blend.

\section{REFERENCES}

[1] Al-Rawi kh.R,Abdulwahid M.Z.,"wear and mechanical properties of epoxy/Mgo-Sio2 hybrid nanocomposites" Iraqi journal of physics, vo.13,No.26,pp58-63,2015.

[2] Awham M. H., "Development and Study of Blended-Base Polymer Composites", Ph D thesis Department of Applied Science, University of Technology, (2006).

[3] Rudin, A., "The Elements of Polymers, Science and Engineering, $3^{\text {rd }}$ edit., Elsevier inc. 2013

[4] Kaw A. K., "Mechanics of Composite Materials", $2^{\text {nd }}$ Edition, Taylor and Francis Group, LLC, NewYork, (2006)

[5] Davis J. R., (Edit), "Tensile Testing", $2^{\text {nd }}$ Ed., ASM International, PP.77-82, (2004).

[6] Kopeliovich D., "Shore (Durometer) Hardness Test", Subs \& Tech last modification.28, Apr., (2012).

[7] Wasan K. Hassan "Study of Fillers Effect From Iraqi Clays on Mechanical and Thermal Properties for Polymers", M.Sc Thesis, Physics Department, University of Baghdad, (2007).

[8] D Selwyn Jebaduri \& A Suresh Babu, "Influence of functionalized multi-walled carbon nanotubes on mechanical properties of glass fiber reinforced polyester composites", Indian Journal of Engineering \& Materials Sciences, Vol. 22, April 2015, pp. 167-174.

[9] Mekhael, S " Study of mechanical properties and thermal conductivity for polymeric composite supported by Aluminum particles and aluminum oxide", MSc thesis department of material engineering, University of Technology, (2007).

[10] Ban Ayyoub Yousif, "Development and Characterization of Ternary Thermosetting Polymer Blends", Ph.D thesis, Deparment of Applied Sciences, University of Technology, (2010).

[11] Iskender Ozsoyl, etal, "The influence of Micro- and Nano-filler content on the mechanical properties of epoxy composites", Journal of mechanical engineering 61 (2015)10, 601-609.

[12] Alhamdani.N.A, Alshawak.N.Dh, "Study of mechanical and thermal properties for Nano composites, ZrO2/PMMA", Dyala journal for pure science, Vol: 12 No.2, April 2016.

[13] Kaftan.A.M, "Study of physical properties for polymeric blends supported by metallic sheets and micro cotton", MSc thesis. Department of applied sciences, University of Technology (2012).

[14] Ahmed.W.I., "Study The Effect of Short Carbon Fibers on Properties of Epoxy Composites Material", MSc thesis, College of education for pure sciences, University of Anbar, (2014) Iraq. 